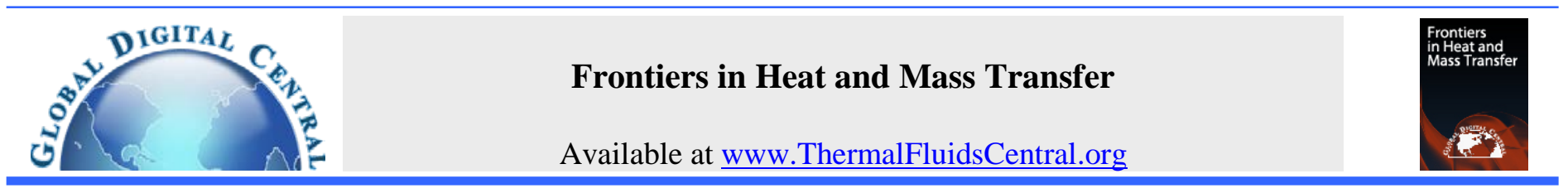

\title{
CFD MODELLING AND VALIDATION OF COMBUSTION IN DIRECT INJECTION COMPRESSION IGNITION ENGINE FUELLED WITH JATROPHA OIL BLENDS WITH DIESEL
}

\author{
Biswajit De*, Rajsekhar Panua \\ Mechanical Engineering Department, National Institute of Technology, Agartala, Tripura, 799055, India
}

\begin{abstract}
This paper presents a pre-mixed combustion model for diesel and Jatropha oil blends combustion studies. Jatropha oil blends are considered as a mixture of diesel and Jatropha oil. CFD package, FLUENT 6.3 is used for modeling the complex combustion phenomenon in compression ignition engine. The experiments are carried out on a single cylinder, four strokes, water cooled direct injection compression ignition engine at compression ratio of 17.5 at full load condition at constant speed of $1500 \mathrm{rpm}$ fuelled with diesel and jatropha oil blends with diesel. The numerical model is solved by considering pressure based, implicit and unsteady solver and the effect of turbulence has taken into account. For turbulence modeling, RNG k- $\varepsilon$ model is used. Sub models such as droplet collision model and TAB model are used for spray modeling. Species transport and pre-mixed combustion model are used for in-cylinder combustion. Computational results for a four stroke single cylinder diesel engine are comparing favorably against experiments. The results are in good agreement with experimental data. The present development yields a basis for detailed CFD studies of diesel and Jatropha oil blends combustion in a four stroke single cylinder diesel engine.
\end{abstract}

Keywords: $k$ - $\varepsilon$ model; pre-mixed combustion model; simulation;

\section{INTRODUCTION}

CFD is an efficient tool for studying fluid flow, mixture formation and combustion in internal combustion engines, where size makes experimentation very expensive. As a rapid and cost effective tool, CFD is being increasingly used in different stages of engine design, optimization and performance analysis. Difficulties arise when simulating a DI engine where the combustion can take place under partially mixed conditions. The combustion model is required to be able to handle with both the premixed and non-premixed burning and their transition. Goldsworthy (2006) investigated a simplified Heavy fuel oil (HFO) evaporation and combustion model, in which the fuel was considered as a mixture of a heavy (residual) and a light (cutter) component. The model was implemented in the CFD code Star-CD, and tested against experimental data for constant volume combustion chambers, for two representative heavy fuels, one of poor combustion quality and one of good combustion quality. The results were compared to experiments and a good agreement was found between measured and computed data for ignition delay, burning rate, and spray and flame structure, including flame liftoff length. A more detailed approach of HFO modeling is presented in the studies of Struckmeier et al. (2009, 2010). In their work, evaporation, ignition and combustion models were further developed, still accounting for a two-component fuel. Their CFD results, obtained with a KIVA-based code, report a good agreement with experimental data in constant volume combustion chambers, in terms of spray and combustion development. Shundoh et al. (1992) investigated that multiple injections divide the total quantity of fuel into two or more injections per combustion event. A pilot injection is also usually defined as an injection where $15 \%$ or less of the total mass of fuel is injected in the first injection. Many researchers are now investigating pilot and split injection as an effective means to simultaneously reduce NOx and soot emissions. He also reported that NOx could be reduced by $35 \%$, and smoke by 60 to $80 \%$, without a penalty in fuel economy if pilot injection was uses in con junction with high pressure injection. Nehmer et al. (1994) studied the effect of split injection in a heavy-duty diesel engine by varying the amount of fuel in the first injection from $10 \%$ to $75 \%$ of the total amount of fuel. They found that split injection better utilized the air charge and allowed combustion to continue later into the power stroke than for a single injection case, without increased levels of soot production. Tow et al. (1994) found that using a double injection with a relatively long dwell on a heavy duty engine resulted in a reduction of particulate emissions by a factor of three with no increase in NOx and only a slight increase in BSFC compared to a single injection. Zhang (1999) used a single cylinder HSDI diesel engine to investigate the effect of pilot injection with EGR on soot, NOx and combustion noise, and found that pilot injection increased soot emissions. The author also showed that reducing the amount of fuel in the pilot injection and increasing the interval between pilot and main injections could reduce the pilot flame area when the main injection starts, resulting in lower soot emissions. Montgomery(1996) simulated a single cylinder version of a Caterpillar 3400 series heavy duty DI diesel engine using Fluent 6.2 and compared to published experimental data. The objective of the study was to validate an ignition model in conjunction with the existing dynamic mesh and spray models against an established data set consisting of six different load and speed conditions (modes) from a federal transient test procedure. An additional focus of the work was the evaluation of the applicability of the current models for predicting production of nitrogen

* Currently in New Business or Academic Affiliation, City, State/Province, Zip Code, Country 
oxides at high temperatures (thermal $\mathrm{NO}_{\mathrm{x}}$ ). Patterson and Reitz (1998) has been developed a new spray model to improve the prediction of model in conjunction with the existing dynamic mesh and spray diesel engine combustion and emissions using the KIVA-II CFD code. The accuracy of modeling the spray breakup process has been improved by the inclusion of Rayleigh-Taylor accelerative instabilities, which are calculated simultaneously with a Kelvin-Helmholtz wave model. This model also improves the prediction of the droplet sizes within a diesel spray and provides a more accurate initial condition for the evaporation, combustion, and emissions models. The objective of the present study is to validate a pre-mixed combustion models against an experimental data set consisting of diesel and jatropha oil blends at full load conditions and at constant speed of $1500 \mathrm{rpm}$.

\section{CFD MODELS}

The modeling of flow field of continuous and dispersed phases of combustion are carried out in detail using a commercial CFD package, FLUENT. The two dimensional in-cylinder, transient and reacting flow system in a direct injection Diesel engine is modeled by solving a set of governing equations from the law of conservation of mass, momentum, energy and species.

\subsection{Turbulence Model}

Turbulence is distinguished by fluctuation of velocity field. The RNG k- $\varepsilon$ model (EI Tahry et al., 1983) is which the turbulent Reynolds number forms of the $\mathrm{k}$ and $\epsilon$ equation are used in conjunction with the algebraic 'law of the wall' representation of flow, heat and mass transfer for the near wall region. The RNG $k-\varepsilon$ model having an advantage to include the effect of swirl compared to the standard $k-\varepsilon$ model, which is important for internal combustion engine combustion analysis. Transport equations for the RNG k- $\varepsilon$ model is defined as,

$\frac{\partial}{\partial t}(\rho k)+\frac{\partial}{\partial x_{i}}\left(\rho k u_{i}\right)=\frac{\partial}{\partial x_{j}}\left(\alpha_{k} \mu_{e f f} \frac{\partial k}{\partial x_{j}}\right)+G_{k}+G_{b}-\rho \in-Y_{M}+S_{k}$

$\frac{\partial}{\partial t}(\rho \in)+\frac{\partial}{\partial x_{i}}\left(\rho \in u_{i}\right)=\frac{\partial}{\partial x_{j}}\left(\alpha_{\in} \mu_{e f f} \frac{\partial \epsilon}{\partial x_{j}}\right)+C_{1 \in} \frac{\epsilon}{k}\left(G_{k}+C_{2 \epsilon} G_{b}\right)$

$-C_{2 €} \rho \frac{\epsilon^{2}}{k}-R_{\epsilon}+S_{\epsilon}$

In these equations, $G_{k}$ characterizes the generation of turbulence kinetic energy; $G_{b}$ is the generation of turbulence kinetic energy due to buoyancy. $Y_{M}$ represents the contribution of the fluctuating dilatation in compressible turbulence. The quantities $\alpha_{k}$ and $\alpha_{\epsilon}$ are the inverse effective Prandtl numbers for $\mathrm{k}$ and $\varepsilon$ respectively. $S_{k}$ and $S_{\epsilon}$ are user defined source terms. The model constants $C_{1 \epsilon}$ and $C_{2 \epsilon}$ in equation have values derived analytically by the RNG theory.

\subsection{Spray breakup Model}

There are mainly two Spray breakup models in fluent, the TAB and the wave model. The distorting droplet effect of TAB model (Huh et al., 1991) is considered in the present study. The equation governing a damped force oscillator is,

$$
F-k^{x}-d \frac{d x}{d t}=m \frac{d^{2} x}{d t^{2}}
$$

where $x$ is the displacement of the droplet equator from its spherical position and the coefficients of this equation are taken from Taylor's analogy;

$$
\frac{F}{m}=C_{F} \frac{\rho_{g} u^{2}}{\rho_{l} r}, \frac{k}{m}=C_{k} \frac{\sigma}{\rho_{l} r^{2}} \text { and } \frac{d}{m}=C_{d} \frac{\mu_{l}}{\rho_{l} r^{2}}
$$

where $\rho_{g}$ and $\rho_{l}$ are the continuous phase and discrete phase densities, $\mathrm{u}$ is the relative velocity of the droplet, $\mathrm{r}$ is the undisturbed droplet radius, $\sigma$ is the droplet surface tension and $\mu_{l}$ is the droplet viscosity, $C_{F}, C_{k}$ and $C_{d}$ are dimensionless constants.

\subsection{Droplet collision Model}

There Droplet collision model (O’Rourke et al., 1981) is which includes tracking of droplets; for estimating the number of droplet collisions and their outcomes. When two parcels of droplets collide then algorithm further establish the type of collision. Only coalescence and bouncing outcomes are measured. The probability of each outcome are calculated from the collision Weber number $(W e l)$ and fit to experimental observation. The Weber number is given as,

$$
W e_{l}=\frac{\rho U_{r e l}^{2} \bar{D}}{\sigma}
$$

where $U_{\text {rel }}$ the relative velocity between two is parcels and $\check{D}$ is the arithmetic mean diameter of the two parcels. The state of the two colliding parcels is modified based on the outcome of the collision.

\subsection{Wall Film Model}

There Spray-wall interaction is an important element of the mixture creation process in diesel engines. In a DI diesel engine, fuel is injected directly into the combustion chamber, where the spray can impinge upon the piston. The modelling of the wall-film inside a DI engine is compounded by the occurrence of carbon deposits on the surfaces of the combustion chamber. This carbon deposit soak up the liquid layer. It is understood that the carbon deposits absorb the fuel later in the cycle. The wall-film model (Bai et al., 1996) in Fluent allows a single constituent liquid drop to impinge upon a boundary surface and form a thin film. Interaction during impact with a boundary and the criteria by which the regimes are detached are based on the impact energy and the boiling temperature of the liquid. The impact energy is defined by,

$$
E^{2}=\frac{\rho V_{r}^{2} D}{\sigma}\left(\frac{1}{\min \left(\frac{h_{o}}{D_{1}}\right)+\frac{\delta_{b l}}{D}}\right)
$$

where $\rho$ is the liquid density, $\mathrm{V}_{r}$ is the relative velocity of the particle in the frame of the wall; $\mathrm{D}$ is the diameter of the droplet and $\sigma$ is the surface tension of the liquid. Here $\delta_{b l}$ is a boundary layer thickness.

\subsection{Combustion Model}

The combustion model is combined with species transport and premixed combustion to simulate the overall combustion process in a diesel engine. This approach is based on the solution of transport equation for species mass fraction. The reaction rates that emerge as source terms in the species transport equation are computed from well known Arrhenius rate expressions. The turbulent premixed combustion model, involves the solution of a transport equation for the reaction progress variable. The premixed combustion model (Colin et al., 2004) thus considers the reacting flow field to be divided into regions of burnt and unburnt species, separated by the flame sheet. The progression of the reaction is therefore the same as the progression of the flame front. The flame front propagation is modeled by solving a transport equation for the scalar quantity $c$, the (Favre averaged) reaction progress variable:

$$
\frac{\partial}{\partial t}(\rho c)+\nabla \cdot(\rho \bar{v} c)=\nabla \cdot\left(\frac{\mu_{t}}{S_{c t}} \nabla_{c}\right)+\rho S_{c}
$$

where $\mathrm{c}=$ reaction progress variable, $\mathrm{Sct}=$ turbulent Schmidt number for the gradient turbulent flux, $S c=$ reaction progress source term $(\mathrm{s}-1)$. The progress variable is defined as

$$
c=\frac{\sum_{i=1}^{n} Y_{i}}{\sum_{i=1}^{n} Y_{i, a d}}
$$

where $\mathrm{n}=$ number of products, $Y_{i}=$ mass fraction of species $\mathrm{i}, \mathrm{Y}_{\mathrm{i}, \mathrm{ad}}=$ mass fraction of species i after complete adiabatic combustion. Based on this definition, $c=0$ where the mixture is unburnt and $c=1$ where 
the mixture is burnt: $c=0$ : unburnt mixture, $c=1$ : burnt mixture. The value of $c$ is defined as a boundary condition at all flow inlets. It is usually specified as either 0 (unburnt) or 1 (burnt).

\section{MODEL DEVELOPMENT}

\subsection{Geometry Development and Meshing of Computational Domain}

In present work, the geometry has been modeled and meshed in preprocessor Gambit 2.4.6 and then it is exported to fluent 6.3 for simulation and prediction. Figure 1 shows the computational domain of two dimensional combustion chamber geometry of the diesel engine with inlet and exhaust ports. Both intake and exhaust ports have been meshed with quadrilateral structured mesh in the zone upstream of the valves and the combustion chamber with triangular structured mesh. The combustion chamber is bowl-in-piston type, which having a hemispherical groove on piston top.

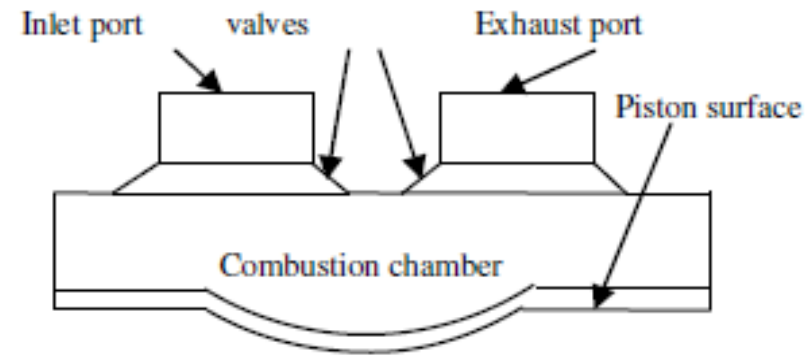

(a)

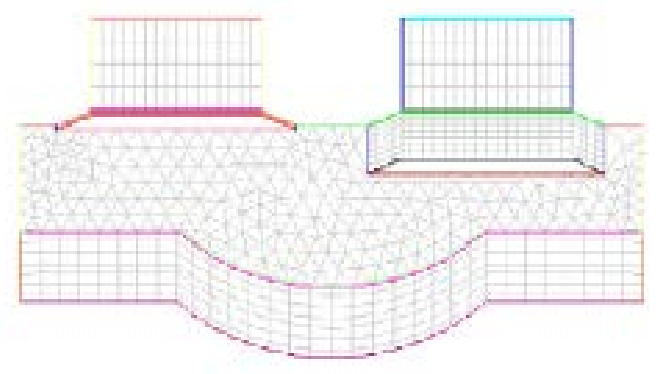

(b)

Fig. 1 Physical model and mesh: (a) Geometry of combustion chamber with valves and (b) Mesh structure of computational domain for model geometry at 600 degree Crank angle

The geometry has been modeled at its zero degree crank angle position at TDC as shown in figure 1(a). Figure 1(b) shows the mesh structure of computational domain for model geometry at 600 degree Crank angle.

\section{MODELING METHODOLOGY}

In the present study, the numerical model is solved as unsteady, first order implicit considering turbulence effects to simulate the internal combustion for the engine. The numerical methodology is segregated pressure-based solution algorithm. For solving species, the discrete phase injection with species transport equation and pre-mixed combustion equations are used. The upwind scheme is used for the discretization of the model equations and a finite-volume-based technique to convert the governing equations to algebraic equations that can solve numerically. The governing equations for mass, momentum and energy equations used and appropriate initial boundary conditions are chosen for combustion analysis.

\subsection{Grid independency tests}

The grid independency test of the model is carried out. It can be observed that increasing the cells beyond 30000 cells does not alter the in-cylinder peak pressure and other variables. Thus the grids that are solved by final volume method are independent beyond 30000 cells at TDC condition.

\section{VALIDATION}

Experiments are performed on a fully instrumented, single cylinder, four strokes, water cooled direct injection compression ignition engine at compression ratio of 17.5 at full load condition at constant speed of $1500 \mathrm{rpm}$ fuelled with diesel and jatropha oil blends with diesel. The specification of test engine is given in the Table 1 and the analyzed results for various physical, chemical and thermal properties of Diesel and Jatropha oil are given in Table 2. Pressure is recorded with crank angle sensor revolution /degree. For digital load measurement strain gauge sensor, range $0-50 \mathrm{Kg}$ with eddy current dynamometer is used. Labview based Engine Performance Analysis software package "EnginesoftLV" is provided for on line performance evaluation. For all settings, the cylinder pressure values are recorded thrice and a mean of these is taken for comparison.

To verify the results from simulation, the pressure data computed is compared against experimental pressure data from experiments. Fig. 2 shows that the computed in-cylinder pressure data from numerical simulation are in good agreement with the experimental data.

Table 1 Specification of the test engine.

\begin{tabular}{|l|l|c|}
\hline S. No & Parameters & Specification \\
\hline 1. & $\begin{array}{l}\text { General } \\
\text { Details }\end{array}$ & $\begin{array}{c}\text { Single cylinder, four stroke } \\
\text { compression ignition engine, } \\
\text { constant speed, vertical, } \\
\text { water cooled, direct injection }\end{array}$ \\
\hline 2. & Stroke & $110 \mathrm{~mm}$ \\
\hline 3. & Bore & $87.5 \mathrm{~mm}$ \\
\hline 4. & Displacement & $661 \mathrm{cc}$ \\
\hline 5. & $\begin{array}{l}\text { Compression } \\
\text { ratio }\end{array}$ & 17.5 \\
\hline 6. & Rated output & $3.7 \mathrm{KW}$ \\
\hline 7. & Rated speed & $1500 \mathrm{rpm}$ \\
\hline
\end{tabular}

Table 2 Properties of mineral diesel and Jatropha oil.

\begin{tabular}{|l|c|c|}
\hline Property & Mineral diesel & Jatropha oil \\
\hline Density $\left(\mathrm{kg} / \mathrm{m}^{3}\right)$ & 841 & 917.5 \\
\hline API gravity & 37.123 & 22.8925 \\
\hline Kinematic viscosity at $40^{\circ} \mathrm{C}(\mathrm{cSt})$ & 2.575 & 36.63 \\
\hline Pour point $\left({ }^{\circ} \mathrm{C}\right)$ & -6 & 4.5 \\
\hline Fire point $\left({ }^{\circ} \mathrm{C}\right)$ & 104 & 275 \\
\hline Cloud point $\left({ }^{\circ} \mathrm{C}\right)$ & 3.5 & 9.5 \\
\hline Flash point $\left({ }^{\circ} \mathrm{C}\right)$ & 72 & 230 \\
\hline Calorific value $(\mathrm{MJ} / \mathrm{kg})$ & 44.864 & 38.6355 \\
\hline Carbon $(\%, \mathrm{w} / \mathrm{w})$ & 80.32 & 76.113 \\
\hline Hydrogen $(\%, \mathrm{w} / \mathrm{w})$ & 12.358 & 10.517 \\
\hline Nitrogen $(\%, \mathrm{w} / \mathrm{w})$ & 1.758 & 0 \\
\hline
\end{tabular}




\section{RESULTS AND DISCUSSIONS}

\subsection{Cylinder pressure rise results}

Figure 2 shows the modeling and experimental in-cylinder pressure at CR of 17.5 operating at full load condition. The modeled cylinder pressure data shows good agreement with experimental results. The maximum pressure rise depends upon the quantity of fuel vaporized during the delay period and occurs in the state of combustion, some degrees after the beginning of combustion.
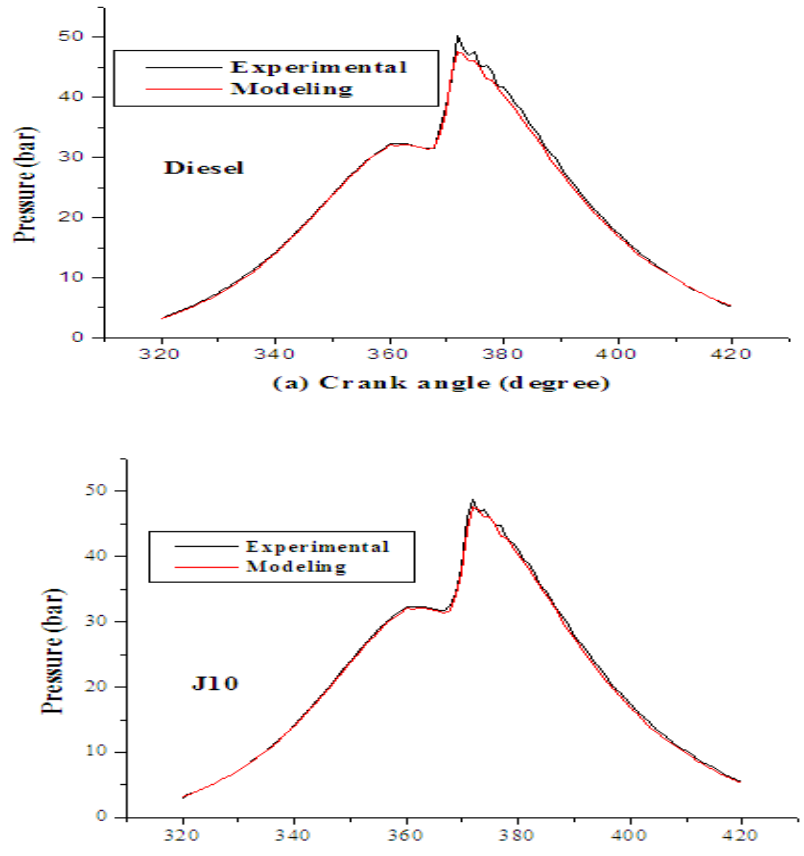

(b) Crank angle (degree)
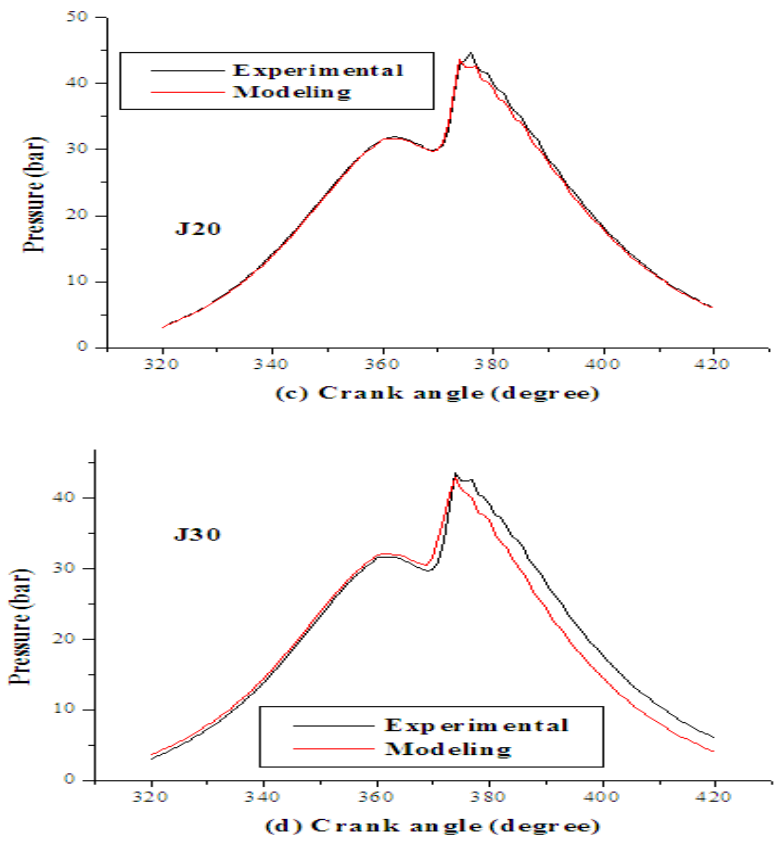

Fig. 2 Comparison between modeling and experimental pressure diagram: (a) diesel fuel, (b) 10\% jatropha oil blend, (c) $20 \%$ jatropha oil blend, (d) 30\% jatropha oil blend.
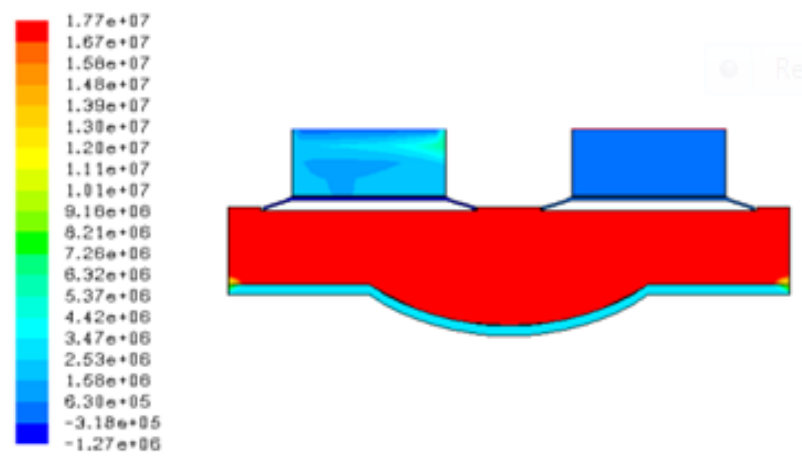

(a)

$5.076+00$
$4.820+00$

4.560 .60

4.310 .60

$4.060+00$

$3.300+00$
$3.650+00$

3.650 .00

$3.300+00$

$3.040+00$

$2.790+00$

$2.540 \cdot 00$

$2.286+00$

$2.030 \cdot 00$

$1.780 \cdot 00$

$1.620+00$

$1.270+00$

$1.010+00$
$7.610-01$

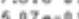

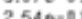

$2.546-0$

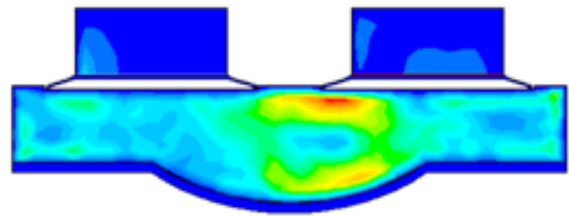

Fig. 3 Contours (a): static pressure of diesel fuel at 350 degree crank angle, (b): velocity magnitude of $10 \%$ Jatropha oil blend at 370 degree crank angle.
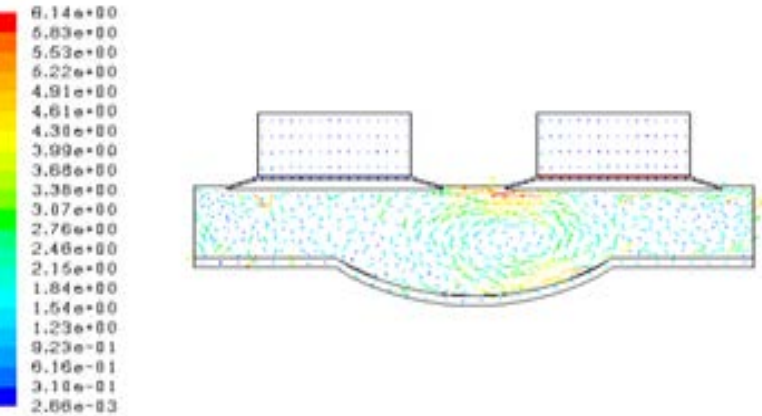

(a) 6.660 .40
$6.330 \times 00$ $6.000+00$ $5.660+00$ $5.330+00$ $8.000 \times 00$
$4.800+00$ $4.686+00$ 4.000 .00 3.070 .00

$3.330+10$

3.000 .00

$2.670+10$

$2.33 e \cdot 00$
2.000 .00

2.070 .00
$1.670 \times 00$

1.340 .00

1.900000

$6.700-01$

$3.376-11$

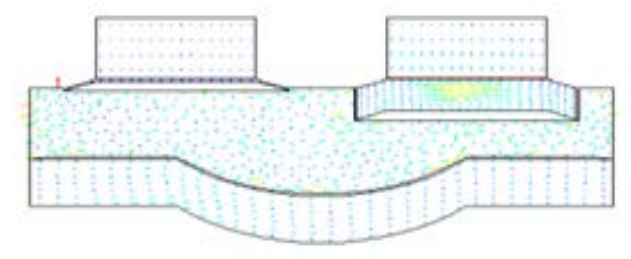

(b)

Fig. 4 Velocity vectors by velocity Magnitude (a): 20\% Jatropha oil blend at 370 degree crank angle, (b): 30\% Jatropha oil blend at 370 degree crank angle. 
Therefore both scale and timing of occurrence of peak pressure are precisely predicted by the model. It can be noted that experimental peak pressure is about 50.24 bars at 372 degree CA and modeling peak pressure is 49.18 bars at 373 degree CA for base line diesel fuel.

The values of the experimental peak pressure for different Jatropha oil blends is such as that for $10 \%, 20 \%$ and $30 \%$ is found to be less than that of diesel fuel by $3.23 \%, 9.08 \%$, and $12.27 \%$. The corresponding modeling pressure for the Jatropha blends is found to be less by $3.17 \%$, $10.12 \%$, and $12.58 \%$ with respect to diesel fuel. Figure 3(a) shows the contours of static pressure of diesel fuel at 350 degree crank angle, (b): Contours of velocity magnitude of $10 \%$ Jatropha oil blend at 370 degree crank angle and 4(a): Velocity vectors by velocity Magnitude of 20\% Jatropha oil blend at 370 degree crank angle, (b): Velocity vectors by velocity Magnitude of 30\% Jatropha oil blend at 370 degree crank angle respectively.

\section{CONCLUSIONS}

The numerical model integrated with sub models includes spray, droplet collision, wall film and combustion model with species transport and pre-mixed combustion theory. The bowl-in piston combustion geometry is used for model construction. In this study RNG $\mathrm{k}-\varepsilon$ model is implemented to confine in-cylinder turbulence. Simulated results of in-cylinder pressure for pure diesel, 10\%, 20\% and 30\% jatropha oil blends with diesel have been analyzed. A good agreement between the modeling and experimental data ensures the accuracy of the numerical prediction of this work. The comparison shows that the present model manages to predict the combustion characteristics quite well. The result reported in this paper illustrate that the numerical simulation can be one of the most powerful and beneficial tool to compute the essential features of combustion parameters for ICE development, optimization and performance analysis.

\section{NOMENCLATURE}

TAB Taylor Analogy Breakup

CFD Computational Fluid dynamics

$G_{k} \quad$ the generation of turbulence kinetic energy

$G_{b} \quad$ the generation of turbulence kinetic energy due to buoyancy

$Y_{M} \quad$ the contribution of the fluctuating dilatation in compressible turbulence

$\alpha_{k}$ and $\alpha_{\varepsilon} \quad$ the inverse effective Prandtl numbers for $\mathrm{k}$ and $\varepsilon$ respectively

$S_{k}$ and $S_{\varepsilon} \quad$ the user defined source terms

$C_{1 \varepsilon}$ and $C_{2 \varepsilon}$ the model constants derived analytically by the RNG theory

$x \quad$ the displacement of the droplet equator from its spherical position

$\rho_{g}$ and $\rho_{l} \quad$ the continuous phase and discrete phase densities

$u \quad$ the relative velocity of the droplet

$r \quad$ the undisturbed droplet radius

$\rho \quad$ the droplet surface tension

$\mu l \quad$ the droplet viscosity

$C_{f}, C_{k}$ and $C_{d}$ dimensionless constants

$U_{\text {rel }} \quad$ the relative velocity between two is parcels

$\check{D} \quad$ the arithmetic mean diameter of the two parcels

$\rho \quad$ the liquid density

$V_{r} \quad$ the relative velocity of the particle in the frame of the wall

$D \quad$ the diameter of the droplet and $\rho$ is the surface tension of the liquid

pbl a boundary layer thickness

C reaction progress variable

Sct turbulent Schmidt number for the gradient turbulent flux

Sc reaction progress source term (s-1). $n \quad$ number of products

Yi mass fraction of species $i$

Yi,ad mass fraction of species $i$ after complete adiabatic combustion

ICE Internal combustion engine

DI Direct injection

CA Crank angle

J10 $\quad 10 \%$ Jatropha oil and $90 \%$ Diesel oil in blends

J20 20\% Jatropha oil and 80\% Diesel oil in blends

J20 20\% Jatropha oil and 80\% Diesel oil in blends

\section{REFERENCES}

Andreadis, P., Zompanakis, A., Chryssakis, C. and Kaiktsis, L., 2011, "Effects of Fuel Injection Parameters on the Performance and Emissions in a Large-bore Marine Diesel Engine," International Journal of Engine Research, 2(1),14-29. http://dx.doi:10.1243/14680874JER511

Bai,C., and Cosman, A.D., 1996, "Mathematical Modeling of Wall Films Formed by Impinges Sprays," SAE Technical Paper Series, 960626.

Colin, O. and Benkenida, A., 2004, "The 3-Zone Extended Coherent Flame Model (ECFM3Z) for Computing Premixed/Diffusion Combustion," Oil \& Gas Science and Technology-Rev, IFP, 59(6), 593609.

\section{http://dx.doi.org/10.2516/ogst:2004043}

EI Tahry, S.H., 1983, "K- $\varepsilon$ Equation for Compressible Reciprocating Engine Flows,” AIAA, Journal of Energy, 7(4), 345-353.

http://dx.doi:10.2514/3.48086

Goldsworthy, L., 2006, “Computational Fluid Dynamics Modelling of Residual Fuel Oil Combustion in the Context of Marine Diesel Engines,” International Journal of Engine Research, 7(2), 181-199. http://dx.doi:10.1243/146808705X30620

Huh, K.Y. and Gosman, A.D., 1991, “A Phenomenological Model of Diesel Spray Atomization,” ICMF1991, Proceedings of International Conference on Multiphase Flow, Tsukuba.

Ng, H. K. and Mahamed Ismail,H., 2012, "Evaluation of Non-Premixed Combustion and Fuel Spray Models for in-cylinder Diesel Engine Simulation,” Applied Energy, 90, 271-279.

http://dx.doi:10.1016/j.apenergy.2010.12.075

Montgomery, D. and Reitz, R. D.,1996, "Six Mode Cycle Evaluation of the Effect of EGR and Multiple Injections on Particulate and NO Emission from a DI Diesel Engine,” SAE paper, 960316.

Mobasheri, R. and Peng, Z., 2012, “Analysis the Effect Of Advanced Injection Strategies on Engine Performance and Pollution Emissions in A Heavy Duty Di-diesel Engine by CFD Modeling,” International Journal of Heat and Fluid Flow, 33, 59-69.

http://dx.doi:10.1016/j.ijheatfluidflow.2011.10.004

Nehmer, D.A., and Reitz, R.D., 1994, "Measurement of the Effect of injection Rate and Split Injections on Diesel Engine Soot and NOx Emissions"” SAE Paper, 940668.

O’Rourke, P.J., 1981, “Collective Prop Effects on Vaporizing Liquid Sprays,” PhD Thesis, University of Princeton.

Patterson, M.A. and Reitz, R.D., 1998, "Model the Effects of Fuel Spary Characteristics on Diesel Engine Combustion and Emission," SAE paper, 980131.

Stamoudis, N. and Chryssakis, C., 2014, “A Two Component Heavy Fuel Oil Evaporation Model for CFD Studies in Marine Diesel Engines,” Fuel, 115,145-153.

http://dx.doi.org/10.1016/j.fuel.2013.06.035 
Struckmeier, D., Tsuru, D., Kawauchi, S., and Tajima, H., 2009, "Multi-Component Modeling of Evaporation, Ignition and Combustion Processes of Heavy Residual Fuel Oil," SAE Technical Paper Series 2009-01-2677, SAE International Powertrains, Fuels and Lubricants Meeting. San Antonio, Texas.

Struckmeier, D., Tajima, H., and Tsuru, D., 2010, “New Application and Modeling of Low Ignitability Fuel for Marine Engines," CIMAC 2010, Paper No. 117, Bergen, Norway.
Shundoh, S., Komori, M., Tsujimura, K., and Kobayashi, S., 1992, "Nox Reduction from Diesel Combustion Using Pilot Injection with High Pressure Fuel Injection,” SAE paper, 920461.

Tow, T.C., Pierpont, A., and Reitz, R.D., 1994, "Reducing Particulate and NOx Emissions by Using Multiple Injections in a Heavy Duty D.I. Diesel Engine," SAE Paper 940897.

Zhang, L., 1999 “A Study of Pilot Injection in a DI Diesel Engine,” SAE paper, 01-3493. 